Cedar blocks six to eight inches in length-the latter is
worth more for wear than the increased cost-are the great worth more for wear than the increased cost-are the great tion with pine, and when well graveled in the first place had a year or two of wear, in order to $\mathrm{Bg}$ gin restore the stony surface gained by the tramping and rolling in of the stone by the horses and vehicles which first pass over them, and
which surface will measurably wear off in a couple of years,
$t$ is wood may reasonably be expected to wear out before $t$ is wood may reasonably be expected to wear out before any material depreciat

\section{NEW COLORING MATTERS.}

$$
\text { P. GREIFr. }
$$

IF one part of chloranil is allowed to act upon two part
of dimethylanilin a deep blue coloration is observ d, even in the cold. On beating to $50^{\circ}$ the reaction is complete, and a bronze-colored melt is obtained, which is insoluble in water,
but gives up to alcohol and acetic acid a deep violet blue but gives up to alcohol and acetic acid a deep violet blue
color of great purity. If instead of dimethylanilin, methyldiphen plete and the yield is high.

SEPARATION OF FATS AND SOAPS. JUSTUB WoLFF,

THE mixture of soap and fat is comminuted as far as possible, mixed with from 10 to 20 parts of purified aniline,
and digested in the water bath, stirting and crushing continally for half to three-quarters of an hour. The solution
is filtered when cold, and the residue is several tines treated with aniline. In the residue is found all the soap, whilst
the resins and fats are in the solutions. These are poured together, mixed with hydrochloric acid and witk: 3 or 4 parts
of water, and when cold shaken with ether.. The ethereal solution on evaporationleaves the unsuponified fats ad resins. The aniline must be

STRIPPING COLLODION TRANSFERS.

Sirce the collodion transfer process has become such a
popular one for the production of enlargements, we have popular one for the production of enlargernents, we have ence column as to the cause of blisters in the transferred print, or the reason why in stripping the picture some parts shie paper that is to be its final support, although there is apparently no reason way the collodion should not leave the
plate freely. We have also beard complaints that when the transfer has been effected the film adheres so loosely to the paper that it comes off when the color is applied, or that it variably arise from a want of knowledge, on the part of the operator, of the properties of the coating on the paper. Tous to that of transferring a carbon print, and the means
gation adopted are precisely similar. At one time the paper that supported the picture 5as prepared by simply floating Saxe
or Rive paper on a plain solution of gelatine and drying it. When required for use a sheet was soaked in cold water and then brought in contact with the picture under water, so as
to avoid air bubbles. When the whole was dry the separa-
tion was completed. The disadvantage of this mode of pro-
cedure is that the pictures take an unduly long time to cedure is that the pictures take an unduly long time to dry,
on account of the large quantity of water absorbed by the gelatine before it becomes suffeiently soft for use, and also by many to be subject to hygrometric influences. For these
reasons it bas been the custom of late years to add to the reasons it bas been the custom of late years to add to the
gelatine solution with which the paper is prepared a certain proportion of chrome alum, so that the coating once dry be comes practically insoluble; yet, when treated with warm
water, it becomes sufficiently adbesive to secure the film in again beinger that $n$ o

again being separated. well adapted for collodion transfers, is to soak three ounces has swelled and become quite soft, then heating to abou $120^{\circ}$. When the gelatine has dissolved, about eight grains of chrome alum dissolved in a couple of ounces of water are is being made. It is then transferred to a flat dish, placed in a water bath, sustained at a temperature of $11^{\circ}$. Upon
this Saxe, Rive, or other fine paper is floated, and afterward dried. the above formula we bave not given a definite quantity for the most important item, namely, the chrome alum, no as it will vary with every kind of gelatine used, some requiring more and some less, so that the exact amount can only
be arrived at by direct experiment. The larger the propor-
tion of alum added the more insoluble the corating will be tion of alum added the more insoluble the ccrating will be
when dry, and, consequently, the hotter the water will have to be to bring it into proper condition for use. The propor-
tions given above will generally be found to work well if the
sample of gelatine use be the photographic." In practice. however, most operators preprinting, as they are thereby saved the trouble of prepara

tion, and it also proves much cheaper than the home
made.
Now, double transfer paper is simply paper coated with a preparation such as we have described, to which is added texture of the paper. We have recently seen some paper
that sppesed to have been enameled after the manner of the old Brinkhoff paper before the gelatinous coating wa applied. By this means the fiber of the paper was com
pletely hidden, which rendered it gpecially suitable for the pleiely hidden, which rendered it ppecinlly suitable for the
productfon of fine work. Paper prepared in the manner we ble, will still absorb water and swell up, provided the wate be heated to $90^{\circ}$ or $100^{\circ}$, and will then acquire a slimy fee
very similar to that of wash leather that has for a long time been steeped in water. But if the soaking of the puper be long continued, and the water hot enough, in time the whole of the coating will be dissolved off. The proper condition
for our present purpose is secured when the coating has be-
come slimy or decidedly gelatinous. If it be allowed to remain in the water long after this stage is reached then there
is the danger of the whole being removed, so that no adhesive means of gum resins, and that be had thus bee
enabled to photograph slightly beyond the lowest limit of material is left to cement the collodion film to the paper.
me visible spectrum. Further researches proved that bro mide of silver could be prepared in tro molecular statesone that already shown, and the other in which absorption
takes place in the red as well as in the blue. This was found sensitive to every radiation. He pointed out that the blue

It is well known to carbon operators that all gelatine films sensitive to every radiation. He pointed out that the blue
containing cbromic salts become more insoluble the longer form of the silver bromide could be converted into the red
they are kept, so that a transfer paper that may only require form by simple friction, and that after friction it was insen-
temperature of $90^{\circ}$ when freshly prepared will perbaps re- tive to the ultra-red radiation.

It is well known to carbon operators that all gelatine films sensitive to every radiation. He pointed out that the blue
containing cbromic salts become more insoluble the longer form of the silver bromide could be converted into the red
they are kept, so that a transfer paper that may only require form by simple friction, and that after friction it was insen-
temperature of $90^{\circ}$ when freshly prepared will perbaps re- tive to the ultra-red radiation. quire as much as $110^{\circ}$ to bring it into a proper condition for Captain Abney then threw upon the screen photographs fter six months' keeping a long immersion in water as hot as $130^{\circ}$ will sometimes be necessary to get it into a good
state for use Eventually it will become so leathery and insoluble that long soaking, even in boiling water, will fail to render it serviceable, and it is the want of knowledge of this
property that has le to many failures in transferring collodion pictures. of the prismatic spectrum was reached. He demonstrated
this on the blackboard, by setting up as ordinates the waveengths of the various portions of the photographs as o It is the practice, we believe, of some who supply transfe paper to note on each roll or parcel the temperature the
water should be to render it fit for use. From what we have aid it will be seen that, even when this is done, it will only owance must always be made by increasing the tempera
ore as it becomes more inoluble ture as it becomes more insoluble by keeping. It has been ture have a marked effect in bastening the insolubility of
gelatinous compounds when in combination with cbromium in a warm and damp atmosphere acquires insolubility much Soner than if preserved under opposite conditions.
We will bere add a lint as to the method of applying the transfer paper. Having been cut into sheets a little less ban glass plates, it is iben soaked in warm water until the
proper condition is arrived at. The collodion film is then proper condition is arrived at. The collodion film is then
fooded with cold water, and the paper gently lowered upon by the aid of a squeegee. The squeegee should not be so
hard and firm as those in use by carbon printers. The India rubber tongue should be both broader and softer, which will
give more elasticity and consequently less pressure. If ton great a force be applied, and the gelatine coating very soft,
there is a danger, when the collodion is of an extremely porous character, of its being forced through the film on to
the glass, and thereby causing adhesion to it.-British Jour nal of Photography.

\section{PHOTOGRAPHING COLORS.}

Eveny photographer is acquainted with the fact that
colors which look light will often photograph dark, while ome colors that look dark photograph light. But I believe practicable to entirely overcome this difficulty where short
porte Such a method is very valuable for copying oil paintings, and 1 use it to great advantage in making negatives of
highly colored prints, and objects for photographs upon throughout.

Negatives of natural scenery, made in this war, are indeverything, whatever the color.
Hovelop richly throughout Hoping it may prove as useful to others as it does to
myself, I will describe the method which I have perI place the object to be photographed in a strong light if possible, and use a quict working objective. directy in front sides nearly half an inch apart. Fill the tank with a solu-
tion of bichromate of potash, containing one part of bichromate to 1,000 parts of water. Focus as usual; then prepare ows:

As soon as the emulsion bas set pour upon it a little alco-
olic solution of chlorophyl (formula belowe, and float it backwards and forwards for about thirty seconds, after
which wash until smooth. Flow with tea organifier (tea half ounce, water ten ounces), rinse, and expose about two in without the tank of yellow.

Develop with the sal-soda developer. (I make this double
he strength recommended by Mr. Newton, nad dilute where exposure is suspected.) If the bichromate of potash soludark; if it be to weak, red will photograph too dark. I
have given the proportions I find perfectly adapted to my To prepare the chlorophyl, first extract everthing soluble n water from myrtle or tea leaves, by treating with a
number of changes of bot water. Then dry the leaves,
and the chlorophy may be extracted at any time by reating about an ounce of leaves with four ounces of bot Myrtie leaves yield the most chlorophyl, the solution
of which should be a deep, pure, green color, and will remain good for a long while if kept in the dark. It In manufacturing Newton's emulsion I find it advanta-
fous a geous to mix it in the morning. Try a plate once each
bour after, and add the chloride as soon as it fogs, which is sometimes within three hours. The emulsion will then
be good at once, and remain so. Be careful to give full
exposures. Better over than under expose, and judicious development will make perfect.
The lantern tank which I use is a " sciopticon tank," made to order with plate glass sides; it cost $\$ 1.25$. Noth
ing could be better. I have made two negatives from a highly colored chromo The effect in the tirst is hard and unsatisfactory-the graduations of light and shade all wrong. The second is
remarkably soft, delicate, and brilliant. The colors phoof this method for making copies of oil paintings will be PHOTOGRAPHY OF THE INVISIBLE. CAPTANN ABNEY, R. E., F.R. S., exhibited recently, befor the Manchester L. \& P. Society, his photographs of the howed that the light transmitted by ordinary bers largely into the composition of

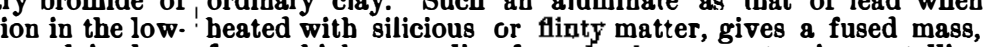
est end of the spoctrum. He then went on to explain how, from which on cooling free alumina separates in crystalline enabled to photograph slightly beyond the lowest limit of
the visibe of the bichromate ond a little oxide of cobalt. In
thectrum. Further researches proved that bro.' specific gravity and in the system of crystallization the

\section{THE RECENT TEXTILE DISPLAY}

THE attractive appearance of the third division of the evoted to textile manufacturers, gave universal satisfaction. marshal, Jas. Dobson (of John \& James Dobson), rode a the bead of the 4,000 forming this division. A remarkably which proclaimed in letters of gold the gact that $50,000,000$ of dollars is the capital invested in textile manufacture in 00 in number, bearing flags ancl banners tastefully made of with carpets of Philadelphia manufacturers, drawn by four "Pray borses, and another, likewise decorated, with the attracted much attention. 2,000 cmployes followed this, and next came a wagon completely covered nith blankets
and rugs, accompanied by 225 men of Seville Scliofield, of had an omnilus drawn by four horses displaying his carpet yarns from River Road, Mand junk. Among others in line
were Heft \& Ogle, Joseph R. Davis, George Grobe, James
Wallace, James \& Davenport, James G. Davis, Charles pencer, etc. Then followed the Fairmount section, num

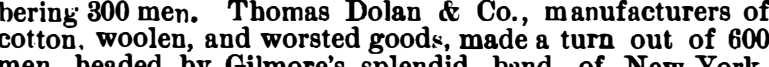
men, headed by Gilmore's splendid hand, of New York,
composed of 65 pieces. The Quaker City Dye Works, of 100 men, was ably led by Mr. Harry H. Green, and pre-
sented a very creditable appearance. Clough \& Carson, of
the Fairmount Dye Works, made a good display. Also
Firth Brothers \& Co., Providence Dye Works. We would there was to be an exbibition of dye-work, did not turn out, there was to be an exhibition of dye-work, did not turn out,
a fact which we exceedingly regret.] Conyers, Button \&
Co. hosierv and knitted goods, had 3 wagons and 150 men Co., hosierv and knitted goods, had 3 wagons and 150 men
J. \& B. Allen, knitted goods, 100 men wearing badges and
regalia. McCallum, Crease \& Co., had 460 uniformed men Charles Spencer \& Son's knitiong mills, 120 men; Schofield \& Branson, 150 men, Thomas F. Stokes \& Sons, woolen
mills; also Joseph Scanlin \& Sons, Foster \& Williams, and Wers. Robert J. Walker's Star Finishing Works, with the Stringfellow, wool and knitting cotton mauufacturers,
had also a tastely decorated wagon. William Wood, cotton and wool manuf acturer, made a creditable turn out. H. gant display made on this occasion by our textile friends but it must be sufficient to say that they have earned a right
to be proud of themselves, as Philadelphia must surely be
proud of them and their works. - Textile Codorist.

ARTIFICIAL DIAMONDS.

AFTER 13 years of experiment, Mr. James MacTear, of the taining " pure crystalline forms of carbon," which, it ap-

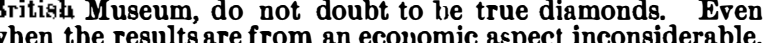
the artificial formation of any substance litherto known solely as a natural product must always be regarded as a
mareat triumph in organic chemistry. In the laboratory the
arrelous chemical discoveries of recent years have in a great measure reduced the production of diamonds to a
question of time and patient experiment, but the general certainty of ultimate success does not in any way detract rom Mr. Mac Tear's brilliant discovery in synthetical minerclaim to priority, for the dual discovery of the planet Nepof other curious coincidences in the history of scientific research, suggest the possibility, if not the probability, of
other alchemists testing with half incredulous delight the tiny erystals which they almost tremble to identify with the of the laboratory that antique impossibilities have become modern diffculties, and the synthesis of the diamond in par-
icular seems a feat which one would be justified in regarding as likely enough. Eleven years ago two German chemists produced from gas tar the coloring principle of
madder, and the Turkey red which we formerly obtained from the fields of France, Holland, and the Levant we now
order from the chemical factory. Last yesr Prof. Baeser,
of Munich University, succeeded in building up ibe blue coloring matter of indigo from the comparatively common umph is none the less because there appears no present bope In the previous year, 1877, oxygen, nitrogen, hydrogen, and we breathe was condensed to a liquid jet; bydrogen was oxide; and the imagination was enabled to add to the terripetrified seas, an atmosphere turning, in a state of disintegration, from invisible gases to strange liquids and new
metals. The production of artificial, not imitation, rubies in the same year by MM. Fremy and Fell seemed especially to herald the production of the diamond. Of all precious

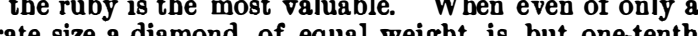
moderate size a diamond of equal weight is but one-tenth handsomely decorated, turned out in force. Shaffner \& substance known as phenylacetic acid, and the scientific tri- 